\title{
SABeres Docentes e Recursos Educacionais ABERTOS: UMA ANÁlISE dA PRESENÇA DESSAS TEMÁTICAS nOS Encontros de Debates sobre o Ensino DE QUímicA (2015 E 2016)
}

\author{
TEACHERS' KNOWLEDGE AND OPEN EDUCATIONAL RESOURCES: AN \\ ANALYSIS OF THE PRESENCE OF THESE TOPICS IN THE MEETING OF \\ DEBATES ON THE TEACHING OF CHEMISTRY (2015 AND 2016)
}

DOI: http://dx.doi.org/10.23926/RPD.2526-2149.2018.v3.n1.p217-230.id184

\section{Ronaldo Eismann de Castro \\ Mestrando em Educação em \\ Ciências (UFRGS) \\ ronaldo.eismann@ufrgs.br}

\section{Maria do Rocio \\ Fontoura Teixeira \\ Doutora em Educação em \\ Ciências (UFRGS) \\ maria.teixeira@ufrgs.br}

Resumo: A partir das importantes contribuições das produções científicas originadas dos Encontros de Debates de Ensino de Química (EDEQs) dos anos de 2015 e 2016, entende-se a relevância da realização de um trabalho com cunho bibliográfico a seu respeito. Para atender a essa demanda, foi realizada uma investigação exploratória dos conteúdos e dos temas dessas produções. Sendo assim, este artigo visa apresentar os resultados do mapeamento e da análise de dados dos trabalhos submetidos nesses dois encontros, a fim de sistematizar os saberes docentes e os recursos educacionais abertos abordados dentro das temáticas apresentadas. O resultado da análise permitiu concluir que os temas relacionados ao saber docente e aos recursos educacionais abertos estão inseridos na grande maioria dos trabalhos, sobressaindo-se, no período verificado, os assuntos relacionados ao saber docente.

Palavras-chave: EDEQ; Recursos Educacionais Abertos; Saberes Docentes.

\begin{abstract}
From the important contributions of the scientific productions originated in the Chemistry Teaching Debates Meetings (EDEQs) in 2015 and 2016, it is understood that there is a great relevance on executing a bibliographical work about its production. In order to attend this demand, an exploratory investigation of the content and the themes of such production was realized. Thus, this article aims to present the results of mapping and analyzing the data collected in the works submitted in these two meetings in order to systematize the teaching knowledge and the open educational resources that were approached within the presented themes. The result of the analysis allowed us to conclude that the themes related to teaching knowledge and open educational resources are inserted in most of the works, standing out in the verified period the subjects related to teaching knowledge.
\end{abstract}

Keywords: EDEQ; Open Educational Resources; Teaching Knowledge. 


\section{INTRODUÇÃO}

Ao longo das últimas décadas, a área de pesquisa do ensino de Química vem ganhando maior destaque no Brasil. No ano de 1980, ocorreu, no Rio Grande do Sul, o primeiro Encontro de Debates de Ensino de Química (EDEQ). Desde então, é possível observar que, com o passar do tempo, houve uma grande ascensão dessa área do conhecimento. $\mathrm{O}$ número expressivo de encontros, debates e publicações científicas referentes ao ensino de Química não deixam dúvidas quanto a isso.

A pesquisa em Educação em Química permite ampliar o aperfeiçoamento do ensino e aprendizagem de Química em todos os níveis. Uma vez que, nesse processo de estudo, há a utilização de regras, conceitos e leis da Química, surgem experiências e práticas e ainda encontros com diversas teorias e saberes de outras ciências. Dentro desse contexto, é possível não só analisar os diversos fatores preponderantes que permeiam o conhecimento da Química entre a comunidade escolar, mas também avaliar o ensino de acordo com o tempo e sua localização geográfica.

Diante de tantos desafios no ensino de Química, a Sociedade Brasileira de Química lançou, em maio de 1995, a revista Química Nova na Escola. Para Bejarano e Carvalho (2000), a evolução da área de pesquisa em educação em Química no Brasil, entre outros fatores, se deve à criação dessa revista, como auxílio para aproximar os professores do Ensino Fundamental e Médio aos resultados das investigações em educação em Química.

O ensino de Química é concebido pelos Parâmetros Curriculares Nacionais para o Ensino Médio (PCNEM) como um ensino contextualizado. Segundo as Orientações Educacionais Complementares aos Parâmetros Curriculares Nacionais (PCN+):

[...] as ciências que compõem a área têm em comum a investigação sobre a natureza e o desenvolvimento tecnológico, e que é com elas que a escola, compartilhando e articulando linguagens e modelos que compõem cada cultura científica, estabelece mediações capazes de produzir o conhecimento escolar, na inter-relação dinâmica de conceitos cotidianos e científicos diversificados, que incluem o universo cultural da ciência Química (BRASIL, 2006, p. 103).

Segundo Moran (2000, p. 137):

[...] uma mudança qualitativa no processo de ensino/aprendizagem acontece quando conseguimos integrar dentro de uma visão inovadora todas as tecnologias: as telemáticas, as audiovisuais, as textuais, as orais, musicais, lúdicas e corporais.

A participação em grupos de estudo e em eventos itinerantes, como o EDEQ, por exemplo, abre um espectro de possibilidades, permeando saberes e recursos educacionais disponíveis para os debates no ensino de Química. Ou seja, trata-se de uma alternativa interessante e viável, para graduandos, pós-graduandos e professores. 
Lima (1996) menciona que a participação em um grupo de estudo para formação continuada dos professores de Química mudou o ensino nas escolas desses profissionais, inclusive em relação ao material didático, que passou a ser elaborado pelos próprios docentes: "as atividades previstas nesses materiais didáticos são estruturadas de modo que os alunos discutam em grupo e apresentem interpretações próprias para fenômenos simples, mas importantes para o entendimento da Química" (LIMA, 1996, p. 13).

Considerando as produções científicas originadas dos EDEQs, em 2017, já em sua trigésima sétima edição, o presente artigo, que faz parte de pesquisa de Mestrado, tem como propósito principal mapear os saberes docentes e os REA abordados nos EDEQs ocorridos nos anos de 2015 e 2016. As análises dos trabalhos ajudam definir e discernir o que são saberes e o que são recursos educacionais abertos apresentados nos referidos Encontros de Debates de Ensino de Química.

Assim, este trabalho contempla uma estrutura de estado do conhecimento, (Morosini e Fernandes, 2014) através do reconhecimento do saber docente e dos recursos educacionais abertos no contexto científico, seguido de uma análise de dados a partir dos registros dos EDEQs, e de uma categorização dos temas dos artigos, refletindo e considerando a pertinência presente nos trabalhos dos dois eventos.

\section{Metodologia}

A metodologia utilizada no trabalho visa ao estabelecimento de uma base interativa entre o pesquisador e o objeto de pesquisa. Inicialmente, foi realizada uma análise dos trabalhos apresentados no EDEQ, em um corte temporal de 2015 e 2016, a partir dos anais dos encontros em foco, num total de 400 resumos de artigos. Assim, foi possível observar um espaço social conceptualizado como campo que se mostra à apreensão em sintonia como um espaço construído de posições "cujas propriedades dependem das posições nestes espaços, podendo ser analisadas independentemente das características de seus ocupantes (em parte determinadas por elas)" (BOURDIEU, 1983, p. 89).

A leitura inicial dos resumos dos artigos serviu para uma categorização prévia, bem como para a classificação de todos os trabalhos, organização dos respectivos dados bibliográficos e elaboração de gráficos para facilitar a visualização das principais conclusões obtidas.

O trabalho tem uma abordagem qualitativa e de natureza descritiva, explicativa e exploratória apoiada em pesquisa de campo. De acordo com Moreira (1999, p. 32), "Pesquisa 
qualitativa é um termo que tem sido usado alternativamente para designar várias abordagens à pesquisa de ensino". A abordagem qualitativa está sendo muito utilizada como metodologia de pesquisa em educação e é a que exprime muito bem a complexidade e a dinâmica dos fenômenos. No processo de classificação, os trabalhos foram ordenados quanto a sua distribuição temporal e nível de escolarização atingido, com a elaboração de gráficos analíticos, através da organização dos dados bibliográficos e de informações complementares.

Após a coleta, os dados foram classificados de forma sistemática através de seleção (exame minucioso dos dados), codificação (técnica operacional de categorização) e tabulação (disposição dos dados de forma a verificar as inter-relações). A análise dos resultados e elaboração de gráficos e de tabelas possibilitaram a extração de conclusões sobre as principais tendências verificadas no conjunto de documentos classificados. Esta classificação proporcionou maior clareza e organização do processo.

O cunho exploratório de análise de conteúdos objetiva, de maneira concreta e operacional, o método de investigação. Investiga-se na metodologia e nas técnicas, respectivamente: a organização da análise, a codificação de resultados, as categorizações, as inferências e a informatização da análise das comunicações. Dentro de um contexto harmonioso, a Análise de Conteúdo partiu de uma organização. A finalidade desse método se dá conforme as conjecturas de interpretação das mensagens e dos enunciados. Os ciclos da Análise de Conteúdo foram organizados em torno de três situações, conforme Bardin (2009, p. 121): 1. A pré-análise; 2. A exploração do material; 3. O tratamento dos resultados: inferência e interpretação.

Inicialmente, o objetivo foi a sistematização para dar continuidade ao processo de analises. Assim, a tarefa da primeira fase foi, além da escolha dos documentos a serem submetidos à análise, a formulação de hipóteses para a elaboração de indicadores para a interpretação final. É preciso apontar que, como partimos de um "universo de documentos de análise" (BARDIN, 2009, p.122), é necessário referir, consequentemente, que concordamos com a ideia de que, para um trabalho mais útil de Análise de Conteúdo, é necessário restringir as amostragens.

"A análise pode efetuar-se numa amostra desde que o material a isso se preste. A amostragem diz-se rigorosa se a amostra for uma parte representativa do universo inicial" (BARDIN, 2009, p. 123). Assim, analisamos todos os resumos dos 400 artigos contidos nos anais do EDEQ dos anos de 2015 e 2016. 


\section{DiscuSSÃo}

\subsection{O SABER DOCENTE}

Diante de tantas informações obtidas na pesquisa, foi fundamental que houvesse uma definição e uma categorização dos dados e das informações relevantes ao trabalho. Dentro da definição dos conceitos que foram analisados, fez-se necessário conceituar o saber docente. $\mathrm{O}$ aspecto visual sustentado pelos professores em relação aos saberes disciplinares, de formação pedagógica e curricular, enaltece muito mais as suas experiências de vida (saberes experienciais), tendo em vista que é sobre esses saberes que os professores dedicam o controle do processo. Na lida cotidiana de suas tarefas e funções, os professores vivenciam situações concretas que exigem certas habilidades para mediar e discernir qual melhor caminho a seguir perante determinada situação apresentada. Dentro dessa prática, não ocorrem situações absolutamente iguais, mas ocorrem situações semelhantes que permitem ao professor fazer o uso de determinadas estratégias, as quais, em outro momento, renderam algum tipo de sucesso em alguma situação semelhante.

Conforme Tardif (2002), os docentes e os saberes não têm um relacionamento limitado à função básica de difundir conhecimentos já adquiridos. $\mathrm{O}$ autor nos mostra que a prática docente tem a função de integralidade de diferentes saberes que comportam várias relações entre si. Apresenta a definição de saber docente como "[...] saber plural, formado pelo amálgama, mais ou menos coerente, de saberes oriundos da formação profissional e de saberes disciplinares, curriculares e experienciais" (TARDIF, 2002, p. 36).

Dentro desse contexto, os saberes do profissional docente são formados por mais de uma origem, são plurais e transpassam qualquer tipo de formação homogênea, compostos também pela história de cada professor.

Segundo Tardif (2002), verificamos um reconhecimento da heterogeneidade do saber docente, com enfoque na importância dos saberes adquiridos pela experiência de cada ser humano. Observamos, ainda, características dos saberes profissionais conforme as etapas e os limites do conhecimento humano, conclusões e métodos dos diferentes ramos do saber científico sendo avaliados em sua validade cognitiva. Esse processo fica incluso como um conjunto de saberes que o profissional docente utiliza na sua rotina de trabalho diário para desenvolver seus projetos, e todas as demandas que a profissão requer.

Freire (2009), Pimenta (2000) e Tardif (2002) deixam claro que os saberes docentes são pluralizados e não são oriundos de uma formação inicial, muito menos terminam por ali. Esse 
caminho que é percorrido e construído possui diversas fontes que consideram o sujeito professor nas suas amplas maneiras de conjugar o verbo ser e estar perante o mundo. Assim, suas experiências de vida, juntamente com diversos outros fatores e aspectos the conferem um caráter próprio e abstrato dentro da formação dos saberes.

Embora tenhamos os saberes docentes classificados e especificados por autores como oriundos de vários conhecimentos de métodos científicos, de técnicas pedagógicas, da apropriação das demandas escolares e da rotina diária do trabalho docente, é preciso ainda mencionar que o profissional docente tem um saber peculiar, que é o resumo de uma equação básica fundamentada na soma de todos esses fatores que se reconhece diariamente na profissão e nos desafios que ela impõe.

\subsection{RECURSOS EDUCACIONAIS ABERTOS}

Segundo a Organização das Nações Unidas para a Educação, a Ciência e a Cultura (UNESCO, 2011; SANTANA; ROSSINI; PRETTO, 2012) podemos definir os Recursos Educacionais Abertos (REA) como qualquer tipo de material apoiado por mídia que se participe sob domínio público, ou com uma licença aberta, e que possa ser manuseado e devidamente ajustado por terceiros. Consequentemente, para ser declarado um REA, é necessário que o material possa ser utilizado, reutilizado, visto e revisto sem que exista qualquer tipo de pagamento de direitos autorais ou alguma autorização autoral adicional.

Assim, conforme a UNESCO, os REA indicam um acesso livre, irrestrito e gratuito para os usuários, bem como podem ser adaptados para um contexto local, ou ainda traduzidos para um idioma de interesse, para permear e atender às necessidades específicas dos alunos.

É preciso lembrar que, mesmo quando não há acesso à internet, pode-se utilizar os recursos educacionais abertos normalmente. Apesar de a grande maioria estar disposta em plataformas digitais, os recursos podem ser salvos em diversos meios (DVD, cartões de memória, pen drive) ou até mesmo utilizados em versões impressas. Com certeza não faltam oportunidades educacionais para a utilização de tais materiais.

Rossini e Gonzalez (2012) nos dizem que, nos recursos educacionais abertos, estão inclusos materiais licenciados abertamente, testes, softwares, vídeos, livros didáticos, jogos e outras ferramentas ou materiais que possam servir como apoio no processo de ensino aprendizagem. Ainda mencionam que, por serem apoiados nas tecnologias, os REA ajudam a proporcionar uma aprendizagem de colaboração e com boa flexibilidade, na troca de 
experiências e práticas de ensino que ajudam a capacitar educadores e trazem benefícios para todos. Conforme Rossini (2010, p. 15):

Os recursos devem ser publicados em formatos que facilitem tanto a utilização e edição, e adaptáveis a diferentes plataformas tecnológicas. Sempre que possível, eles também devem estar disponíveis em formatos que sejam acessíveis às pessoas com deficiências e a pessoas que não têm ainda acesso à internet.

Dentro desse contexto, Ayuste, Gros e Valdivieso (2012, p. 32) definem o conceito "aberto" com um amplo significado. Classificando os recursos como bens públicos, menciona a produção de materiais como formato e padrão livres e, no âmbito social, defende que eles provocam a liberdade de uso, adaptação e troca.

Como política pública, o REA é mencionado no Plano Nacional de Educação (PNE), em 2014, aparecendo entre as metas para a busca de melhoria na qualidade da Educação Básica. $\mathrm{O}$ item 7.11 do documento refere:

Selecionar, certificar e divulgar tecnologias educacionais para a Educação Infantil, o Ensino Fundamental e o Ensino Médio, assegurada a diversidade de métodos e propostas pedagógicas, com preferência para softwares livres e recursos educacionais abertos, bem como o acompanhamento dos resultados nos sistemas de ensino em que forem aplicadas (BRASIL, 2014, p. 58).

Ficam evidentes a relevância e a importância do REA dentro do processo de ensinoaprendizagem nas mais diversas situações do cotidiano educacional em que possam estar inseridos. Da mesma forma, não se pode deixar de mencionar que a ampliação e a facilidade do acesso às tecnologias de informação criaram situações capazes de contribuir, de forma favorável, à educação aberta, na qual o aluno é coautor do processo de ensino-aprendizagem juntamente com o professor. Nessa perspectiva figura, entre outras formas de ensino, o ensino a distância.

Nesse cenário, encontram-se também os Objetos de Aprendizagem (OA), que podem ser recursos digitais ou não, com fins educacionais, sendo considerados: vídeos, imagens, textos e diversas mídias equalizadas entre si para uma aplicabilidade de multimídia na educação.

\section{AnÁlise dos DADOS}

A análise dos resumos permitiu, conforme disposto na metodologia, criar-se planilhas com os assuntos dos artigos apresentados nos EDEQs de 2015 e 2016. Verificou-se quais trabalhos apresentavam a necessidade ou a disponibilidade de recursos educacionais e quais trabalhos levavam como principal base o saber e as práticas dos seus autores, uma vez que a literatura aponta para a importância do uso desses recursos e salienta as relações entre o saber docente e o fazer docente. 
Observou-se que os debates e as reflexões sobre a formação de professores perfazem a maior quantidade de artigos apresentados nos dois anos de evento analisados, chegando a um total de 62 artigos dos 400 citados nos eventos. Esse fato pode relacionar-se ao destaque do professor como personagem principal nos processos de inovações e mudanças, dentro da ótica de supervalorização do profissional docente como indivíduo. Partindo dessa percepção, vários autores têm apresentado anseios e preocupações quanto a uma provável criação de um praticismo daí decorrente, para o qual seria necessária somente a prática na construção do saber docente; de um provável individualismo, originado de uma reflexão própria; de uma possível soberania, considerando que a concepção reflexiva é satisfatória para a resolução dos problemas da prática, sem clareza das origens das circunstâncias que as gerou, o que pode levar a uma simplificação inadequada da reflexão (PIMENTA, 2002, p. 22).

É preciso lembrar também que o professor reflexivo não trabalha como um simples transmissor de conteúdos, mas em sua relação com alunos, colegas e toda comunidade escolar, tem a competência de pensar e repensar sua prática, enfrentado suas atitudes e aquilo que julga acreditar como verdadeiro e certo para o seu trabalho, bem como os possíveis produtos que elas conduzem. Dessa maneira, fica muito clara a real necessidade de fazer as adequações pertinentes das teorias utilizadas em sala de aula com o cotidiano e a realidade do contexto dos discentes, e não se basear em teorias desconexas da realidade dos aprendizes.

Alarcão (2005) define o professor reflexivo, descrevendo-o como um profissional que precisa saber quem é e os motivos pelos quais atua, tendo ciência do lugar que ocupa na sociedade. A autora ainda acrescenta que "os professores têm de serem agentes ativos do seu próprio desenvolvimento e do funcionamento das escolas como organização ao serviço do grande projeto social que é a formação dos educandos" (ALARCÃO, 2005, p. 177).

Outra perspectiva importante é mostrada no gráfico abaixo, do evento de 2016: 
Figura 1 - Artigos apresentados no $36^{\circ}$ EDEQ - 2016

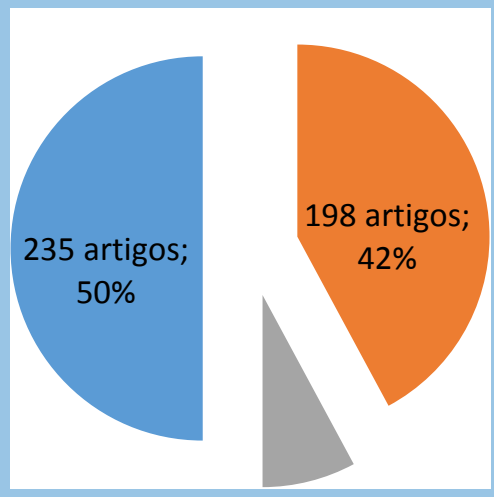

Artigos com assuntos relacionados aos saberes docentes.

Artigos com assuntos relacionados aos recursos educacionais abertos.

Total de artigos

37 artigos; $8 \%$

Fonte: Autores (2018)

A mesma perspectiva aparece no evento de 2015:

Gráfico 2 - Artigos apresentados no 35 EDEQ - 2015

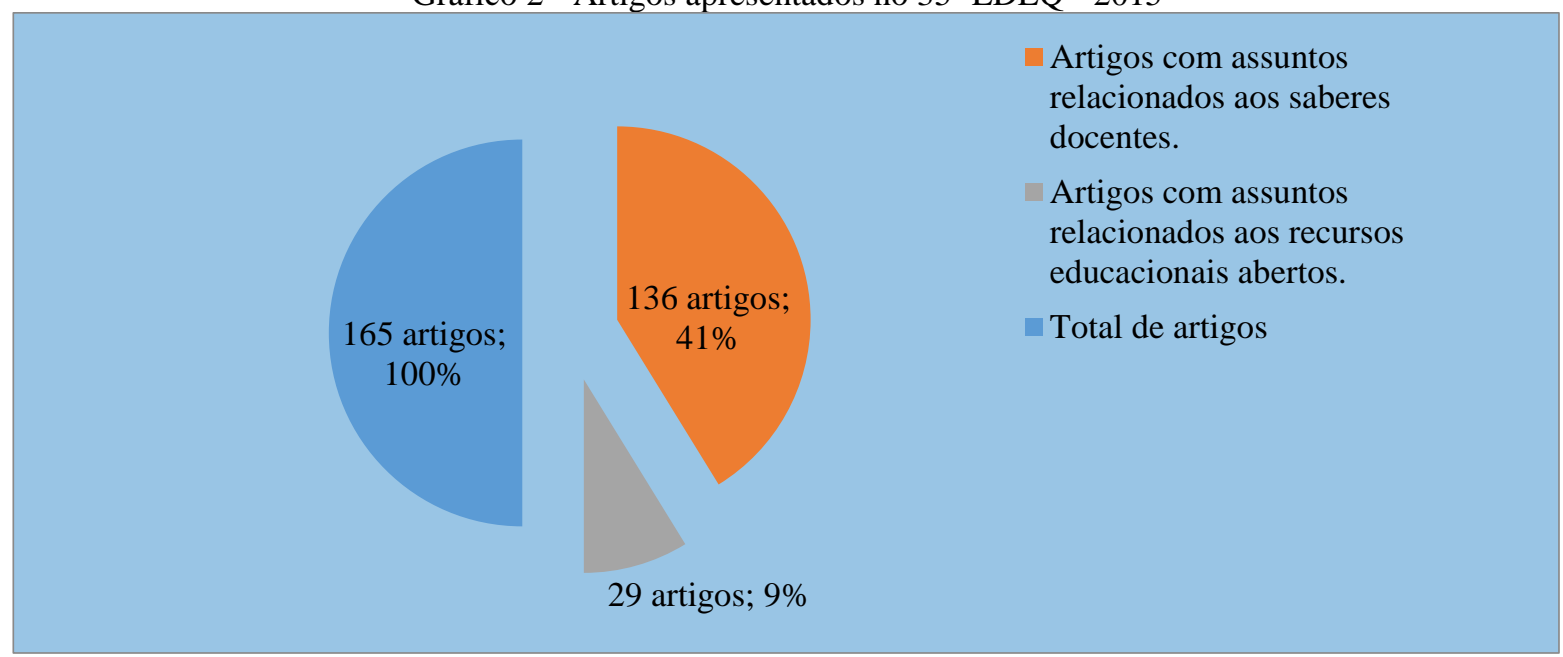

Fonte: Autores (2018).

A ampla relevância do saber docente é contemplada nos dois eventos estudados neste trabalho, começando pela grande quantidade de trabalhos relacionados aos debates e às reflexões sobre a formação de professores. Entretanto, foram contabilizados todos os artigos analisados a fim de fornecer dados mais precisos dentro do processo. Nas tabelas abaixo, não foram apontados temas que tenham sido publicados em somente um artigo.

\section{Categorias}

Tabela 1 - Temas dos artigos apresentados ao $35^{\circ}$ EDEQ - 2015

\begin{tabular}{|l|r|}
\hline Debates e reflexões sobre a formação de professores & 25 \\
\hline Contextualização no ensino de Ciências/Química & 13 \\
\hline Uso de jogos no ensino de Química & 10 \\
\hline Oficinas no ensino de Química e Ciências & 10 \\
\hline
\end{tabular}


Ciência, tecnologia, sociedade e meio ambiente

Experimentação cientifica na educação básica

Interdisciplinaridade

Educação ambiental e agrotóxicos

Análise de livro didático

Mídias digitais/sociais como ferramenta de ensino a distância

Construção do conhecimento e epistemologia

Estratégias e métodos para inclusão de alunos com deficiência

Aplicativo de celular para tabela periódica

Experimentação cientifica no Ensino Superior

Ensino de química e o ENEM/Temas geradores

O ensino de Química como concepção discente

Teatro e Química no cotidiano

Elementos químicos, substâncias químicas, plantas medicinais no ensino de Química

PIBID Química UFRGS/IFC

Condutividade elétrica, ligações iônicas

Análise de produção textual para ensino de Química

Estratégias e ensino de inclusão

Gestão de resíduos químicos

Educação e consumo consciente

O tema “Água” como ensino de Química

Discussão de currículo no ensino de Química

Temas abordados em somente uma publicação

Total de artigos apresentados no evento

Fonte: Autores (2018).

Categorias

Tabela 2 - Temas dos artigos apresentados ao $36^{\circ}$ EDEQ - 2016

\begin{tabular}{|l|r|}
\hline Debates e reflexões sobre a formação de professores & 37 \\
\hline Experimentação cientifica na educação básica & 25 \\
\hline Interdisciplinaridade & 20 \\
\hline Uso de jogos no ensino de Química & 15 \\
\hline Contextualização no ensino de Ciências/Química & 15 \\
\hline Oficinas no ensino de Química e Ciências & 12 \\
\hline Análise de livro didático & 7 \\
\hline Elementos químicos, substâncias químicas & 7 \\
\hline PIBID Química UFRGS/IFC & 7 \\
\hline Educação ambiental e agrotóxicos & 6 \\
\hline
\end{tabular}




\begin{tabular}{|l|r|}
\hline Mídias digitais/sociais como ferramenta de ensino a distância & 6 \\
\hline Construção do conhecimento e epistemologia & 5 \\
\hline Ciência, tecnologia, sociedade e meio ambiente & 5 \\
\hline Estratégias e métodos para inclusão de alunos com deficiência visual & 5 \\
\hline Análise de produção textual para ensino de Química & 4 \\
\hline Aprendizagem e proposta didática & 4 \\
\hline Estratégias de ensino/modelos atômicos & 3 \\
\hline Aplicativo de celular para tabela periódica & 3 \\
\hline Estratégias e ensino de inclusão & 3 \\
\hline Olhar reflexivo sobre avaliação em Ciências & 3 \\
\hline Condutividade elétrica, ligações iônicas & 2 \\
\hline Educação de Jovens e Adultos & 2 \\
\hline Lixo eletrônico e descarte de materiais & 2 \\
\hline O site FISQUIM e o uso de programas para ensino de química & 2 \\
\hline Uso de filmes como metodologia no ensino de Química & 2 \\
\hline Gestão de resíduos químicos & 2 \\
\hline Discussão sobre jogos didáticos como metodologia de ensino & 2 \\
\hline O ensino de Química como concepção discente & 2 \\
\hline O uso de história em quadrinhos e desenho animado para qualificar a leitura do ensino de & 2 \\
\hline Química & 25 \\
\hline Temas abordados em somente uma publicação & $\mathbf{2 3 5}$ \\
\hline Total de artigos apresentados no evento & \\
\hline
\end{tabular}

Fonte: Autores (2018).

O grande número de trabalhos que envolvem a temática saberes e prática docentes são considerados por André et al. (1998) como uma progressão na demarcação do campo de formação de professores. Conforme já apurado anteriormente, o foco privilegiado das pesquisas passa a ser a geração, as exibições e os saberes e práticas do professor.

Em resumo, a formação analógica da identidade do professor é concebida como um processo amplo e complexo que tem, através dos saberes docentes, uma fonte constante de subsídios para seguir em frente conforme as demandas exigidas na profissão. Fica muito evidente que todo o pluralismo da formação docente já fundamentado através de alguns autores neste trabalho é amplamente descrito no vasto espectro dos trabalhos apresentados nos dois eventos. É preciso mencionar, principalmente durante a formação inicial, que os saberes docentes necessitam de um forte investimento para preparar o futuro profissional para as demandas que a profissão exige. Tal exigência parece concordar com o fato de que a grande maioria dos trabalhos apresentados pertence a alunos dos cursos de graduação.

É possível constatar, no período analisado, que temos a produção de 66 artigos (equivalente a $16,5 \%$ ) que apresentam algum assunto relacionado ao REA. Analisando em 
moldes nacionais, os Recursos Educacionais Abertos são uma ferramenta de fundamental importância para dissipar e universalização do conhecimento a partir de escolas e universidades. Ainda que nem sempre seja alcançado o objetivo esperado, entende-se que o sucesso desses recursos nos possibilita pensar que essa seja uma alternativa viável para criarmos sistemas de colaboração de conteúdos. Esses fatores são fundamentais também para a disponibilização de vários recursos importantes dentro do contexto educacional em que estamos inseridos atualmente. Quando falamos sobre educação aberta, não podemos deixar de olhar também para o cenário educacional mundial, em que a necessidade de ampliação da educação com custo reduzido também está em ascensão constantemente. Nesse sentido, os REA aparecem como um modelo de empreendedorismo para práticas inovadoras.

\section{CONSIDERAÇÕES FINAIS}

Dentro do propósito deste estudo, temos algumas considerações sobre a abordagem dos trabalhos apresentados no EDEQ, no período considerado, acerca dos saberes e práticas docentes e dos recursos educacionais abertos.

Observando as áreas temáticas do evento, é possível verificar, pela análise dos artigos, que os saberes e os recursos educacionais abertos permeiam todos os trabalhos mapeados nesta pesquisa. O tema saberes e a prática docente é bastante expressivo em relação ao quantitativo total de trabalhos dos EDEQ, inclusive na linha da qual faz parte. Entretanto, nota-se que os recursos educacionais abertos ainda demandam um espaço relativamente pequeno nas linhas do evento, o que mostra uma contradição em relação ao que é preconizado pelos parâmetros curriculares nacionais. A maior expressividade de trabalhos com essa temática ocorre no $36^{\circ}$ EDEQ, no ano de 2016, quando há um aumento significativo do número de artigos, o que evidencia um maior interesse da comunidade acadêmica no uso dos recursos educacionais abertos.

Os trabalhos abrangem todas as áreas do ensino de Química com destaque para área de ensino e aprendizagem. As mídias digitais estão entre as maiores quantidades de exemplos dos REA.

A fonte de dados dos artigos também é bastante diversificada, envolvendo professores dos diferentes campos de atuação da área da Química, bem como mestrandos e licenciandos dos cursos de Química. Essa diversidade temática indica que professores e pesquisadores estão buscando informações sobre os saberes docentes e os recursos educacionais abertos em todos os campos e níveis relacionados ao ensino de Química. 


\section{REFERÊNCIAS}

ANDRÉ, M. et al. Estado da Arte da Formação de Professores no Brasil. Educação \& Sociedade, v. 20, n. 68, dez. 1999. Disponível em: <http://www.scielo.br/pdf/es/v20 n68/a15v2068.pdf $>$. Acesso em: 7 abr. 2018.

ALARCÃO, I. (coord.). Formação reflexiva de professores: estratégias de supervisão. Porto: Porto Editora, 2005.

AYUSTE, A.; GROS, B.; VALDIVIELSO, S. Sociedad del Conocimiento. Perspectiva Pedagógica. In: ARETIO, Lorenzo Garcia. (org). Sociedad del Conocimiento y Educación. Madrid: Universidad Nacional de Educación a Distancia, 2012. p. 17-40.

BARDIN, L. Análise de Conteúdo. Lisboa: Edições 70, 2009.

BEJARANO, N. R. B.; CARVALHO, A. M. P. A educação química no Brasil: uma visão através das pesquisas e publicações da área. Educación Química, v. 11, n. 1, p.160-167, 2000.

BRASIL. Orientações Educacionais Complementares aos Parâmetros Curriculares Nacionais: Ciências da Natureza, Matemática e suas Tecnologias. Brasília: Secretaria de Educação Média e Tecnológica, 2006.

BRASIL. Lei 13.005, de 25 de junho 2014. Aprova o Plano Nacional de Educação -PNE 2014-2024 e dá outras providências. Presidência da República. Casa Civil. Subchefia para Assuntos Jurídicos. Brasília: DF, 2014.

BOURDIEU, P. Questões de sociologia. Rio de Janeiro: Marco Zero, 1983.

FREIRE, P. Pedagogia da autonomia: saberes necessários à prática educativa. São Paulo: Paz e Terra, 2009.

LIMA, M. E. C. C. Formação continuada de professores de química. Química Nova na Escola, n. 4, 1996. Disponível em 〈http://qnesc.sbq.org.br/online/qnesc04/relatos.pdf〉. Acesso em: 19 out. 2017.

MORAN, J. M. Ensino e aprendizagem inovadores com tecnologias. Informática na Educação: Teoria \& Prática, Programa de Pós-Graduação em Informática na Educação, Porto Alegre, v. 3, n. 1, p. 137-144, set. 2000. Disponível em: $<$ http://www.pucrs.br/ciencias/viali/tic_literatura/artigos/tics/Ensino\%20e\%20aprendizagem \%20inovadores\%20com\%20tecnologias.pdf>. Acesso em: 14 set. 2017.

MOREIRA, M. A. Pesquisa em ensino: o vê epistemológico de Gowin. [S.1.]: Editora Pedagógica e Universitária, 1999.

MOROSINI, M. C. FERNANDES, C. M. B. Estado do Conhecimento: conceitos, finalidades e interlocuções. EDUCAÇÃO POR ESCRITO, Porto Alegre, v. 5, n. 2, p. 154-164, 2014. Disponível em:

$\langle$ http://revistaseletronicas.pucrs.br/ojs/index.php/porescrito/article/view/18875>. Acessado em: 10 jun. 2018. 
PIMENTA, S. G. (Org.). Saberes pedagógicos e atividade docente. São Paulo: Cortez, 2000 .

PIMENTA, S. G. Professor reflexivo: construindo uma crítica. In: PIMENTA, S. G.;

GHEDIN, E. (Orgs.). Gênese e crítica de um conceito. São Paulo: Cortez, 2002.

ROSSINI, C.; GONZALEZ, C. REA: O debate em políticas pública e oportunidade para o mercado. Centro Esportivo Virtual (CEV), 2002. Disponível em:

〈http://cev.org.br/arquivo/biblioteca/4032710.pdf>. Acesso em: 10 nov. 2017.

ROSSINI, C. Tecnologia e Educação: colaboração e liberdades "O Caso do Brasil" Brasília: Fellow da Universidade de Harvard, 2010. Disponível em:

$<$ http://docplayer.com.br/40725948-Tecnologia-e-educacao-colaboracao-e-liberdades-o-casodo-brasil.html>. Acesso em: 10 nov. 2017.

SANTANA, B.; ROSSINI, C.; PRETTO, N. (org.). Recursos Educacionais Abertos: práticas colaborativas e políticas públicas. Salvador: EDUFBA/São Paulo: Casa da Cultura Digital, 2012.

TARDIF, M. Saberes docentes e formação profissional. Petrópolis: Vozes, 2002.

Submetido em: 11 de abril de 2018. Aprovado em: 16 de junho de 2018. 